\title{
Leyes de comunicación en América Latina: derecho a la comunicación con perspectiva de género
}

\author{
Luisa Ochoa Chaves ${ }^{1}$, Angélica Castro Camacho² \\ y Esteban Cubero Hernández ${ }^{3}$
}

\section{Resumen}

Recepción: 16 de agosto de 2017 / Aprobación: 29 de setiembre de 2017

En el artículo se analizan las legislaciones relacionadas con la comunicación y el género de nueve países de América Latina, con el fin de identificar, mediante el análisis de contenidos, los modos en que las leyes transversalizan el derecho a la comunicación y la perspectiva de género. Como resultado, se presenta un breve resumen de cada uno de los contextos nacionales, se analiza cómo se entiende el género y el derecho a la comunicación en cada país, se crean tres casos para clasificar los países estudiados - desde los más avanzados a los más rezagados en la transversalización$\mathrm{y}$, finalmente, se identifican los instrumentos internacionales y las acciones afirmativas para transversalizar el género en clave de comunicación.

\section{Palabras clave}

Libertad de expresión; transversalización; género; leyes; legislación

\section{Abstract}

The article analyzes the laws related to communication and gender of nine Latin American countries in order to identify, by analyzing content, the ways in which the right to communication with gender perspective is mainstreamed. We present a brief summary of each national context, analyze how gender and the right to communication in each country is understood, create three types of cases to rank the countries -from the most advanced to the most laggards in the mainstreaming- of the right to communicate with a gender perspective, and finally, we identified international instruments and affirmative actions for the gender mainstreaming in communication key.

\section{Keywords}

Freedom of expression; mainstreaming; gender; laws; legislation

1 Colombiana-estadounidense. M. Sc. en Comunicación por la Universidad de Costa Rica (UCR). Docente de la Escuela de Ciencias de la Comunicación Colectiva e Investigadora en el Centro de Investigación en Comunicación (CICOM), ambos de la UCR. Correo electróinico: luisa.ochoa@ucr.ac.cr

2 Costarricense. Estudiante de Bachillerato en Ciencias de la Comunicación Colectiva con énfasis en Periodismo, en la UCR. Correo electrónico: anncastro95@gmail.com

3 Costarricense. Estudiante de Bachillerato en Ciencias de la Comunicación Colectiva con énfasis en Periodismo, en la UCR. Correo electrónico: ecuberoh12@hotmail.com 


\section{Resumo}

O artigo analisa as políticas públicas relacionadas à comunicação e ao gênero de nove países da América Latina, a fim de identificar, através da análise de conteúdo, as formas em que as leis transversalizam o direito à comunicação e a perspectiva de gênero. Como resultado, apresenta-se, em primeiro lugar, um breve resumo de cada um dos contextos nacionais. Em segundo, analisa-se como o gênero e o direito à comunicação são compreendidos em cada país. Em terceiro, criam-se três tipos de casos para classificar os países estudados, desde os mais avançados até os mais atrasados na transversalização. Finalmente, identificam-se instrumentos internacionais e ações afirmativas para transversalizar o gênero em elemento chave de comunicação.

\section{Palavras chave}

Direito à comunicação; sistema de gestão de gênero; transversalização; leis; gênero; legislações

\section{Introducción}

En este artículo se analizan algunas leyes relacionadas con la comunicación y el género de nueve países de América Latina: Argentina, Bolivia, Costa Rica, Ecuador, El Salvador, México, Paraguay, Uruguay y Venezuela 4 . Se busca aportar elementos a la discusión sobre las formas de transversalizar la perspectiva de género en las legislaciones de comunicación en América Latina. Esta investigación se encuentra inscrita en el Centro de Investigación en Comunicación (ClCOM), de la Universidad de Costa Rica, y con ella se quiere aportar a la construcción de una serie de lineamientos y recomendaciones para la transversalización del género y el derecho a la comunicación en legislaciones sobre comunicación.

En la primera parte del artículo se presenta, de manera breve, el abordaje teórico y metodológico de la investigación; luego, se contextualiza el estado de los debates sobre las legislaciones en comunicación en los países estudiados y se construyen tres tipologías para abordar los modos como se ha transversalizado, o no, la perspectiva de género en la comunicación. Finalmente, se ofrecen tres apartados adicionales: 1) un abordaje de la manera como son conceptualizados el derecho a la comunicación y la perspectiva de género en las leyes estudiadas, 2) los instrumentos internacionales que sirven de fuentes de interpretación y 3) las acciones afirmativas que promueven el ejercicio del derecho a la comunicación. A manera de conclusión, se definen algunas líneas de trabajo para la transversalización de género y el derecho a la comunicación en las leyes que abordan estos dos ámbitos. 


\section{Abordaje teórico: derecho a la comunicación con perspectiva de género}

El derecho a la comunicación es definido como un atributo innato en el ser humano para expresarse, lo que es un requisito para su participación integral en la sociedad (Andrade, 2007). Abarca otros derechos como difundir y recibir información, expresarse en igualdad de condiciones y oportunidades, investigar, participar en política, la libertad de prensa, el acceso a la información pública y, en general, para el ejercicio de los derechos sociales, políticos, económicos, culturales (Herrera, 2013, p. 527). Se trata de un derecho esencial para la democracia, ya que forma parte de su corpus ético y debe actuar como articulador de todas sus dinámicas sociales y políticas, pues respalda la necesidad irremplazable de una comunicación constante entre Estado y ciudadanía (Andrade, 2007, p. 52). El derecho a la comunicación se diferencia de la libertad de prensa y a la información porque enfrenta los retos de un nuevo contexto. La libertad de prensa surge para garantizar la libre expresión, especialmente de los medios de comunicación; el derecho a la información nace como respuesta a la necesidad de proteger tanto a productores como a destinatarios de la información. El derecho a la comunicación, en cambio, se basa en la necesidad de garantizar que todas las personas no solo accedan a la información, sino que puedan producirla y transformarla en conocimiento (Saffon, 2007, pp. 18-20).

Por su parte, el género se contextualiza en una comunicación patriarcal que invisibiliza identidades de género y orientaciones sexuales fuera de la norma cisgénero y heterosexual, la cual perpetúa estereotipos, naturaliza violencias y espectaculariza y frivoliza mensajes. Además, reconoce que los medios de comunicación son mecanismos de socialización, reproducción de valores y de representaciones sociales que intervienen en la creación de relaciones de poder injustas y desiguales entre géneros e inciden en cómo se organiza la sociedad, cómo se ponen en práctica las discriminaciones y quiénes definen las reglas de su funcionamiento junto con las normas de conducta adecuadas para cada género.

Desde la perspectiva de género, resulta fundamental transversalizar las políticas públicas ${ }^{5}$ de comunicación. Como se indica en los compromisos de la Plataforma de Acción de Beijing (Naciones Unidas, 1995, p. 94), los Estados tienen responsabilidades en relación con evitar la comunicación sexista y la cosificación del cuerpo de la mujer en los medios de comunicación. De igual forma, estos deben promover su acceso democrático en la estructura de

5 En esta misma línea, se ha hecho un esfuerzo por elaborar guías para la transversalización del enfoque de género en políticas públicas (Perú, MIMP, 2013) relacionadas con el medio ambiente (Ecuador, Larrea, 2011), políticas en salud (Organización Mundial de la Salud y Organización Panamericana de la Salud, 2013), acción local (República Dominicana, Auradou, Castillo y Pola 2007) y en comunicación (SICA, 2011). 
producción, trabajo, cargos directivos y perspectiva de contenidos. El asunto de transversalizar la perspectiva de género en la comunicación resulta fundamental y urgente, dado que:

los medios de comunicación no reflejan la realidad, sino que la construyen. Construyen subjetividades de acuerdo con lógicas de clase y lógicas de género. Los medios de comunicación, en muchos países de América Latina, han estado históricamente asociados a los intereses de unas pocas familias que lograron consolidar una matriz hegemónica de la propiedad de los medios; una elite comunicacional que excluyó a los pueblos y su derecho a la comunicación, pero que también ha venido acompañada de una matriz hegemónica de la propiedad simbólica de esos medios. Y lo cierto es que esa matriz económica puede ser, desde mi punto de vista, más simple de modificar que la simbólica, que la cultural, aun con todas las complejidades que implica (Chaher, 2014, p. 12).

Sandra Chaher actualiza, en el 2016, su investigación sobre políticas públicas y perspectiva de género en América Latina (p. 18). Esta reconoce que ha habido avances para el reconocimiento de los derechos basados en género y también de orientación sexual, así como en la regulación de la violencia mediática y simbólica, no obstante, también asegura que el impacto de estas acciones sigue siendo bajo y más bien esporádico. De acuerdo con la autora6:

En la mayoría de nuestros países tenemos normativa que recoge principios de no discriminación por razones de sexo y género, y en algunos se ha avanzado específicamente en la regulación de la violencia simbólica y mediática; sin embargo, esto no ha implicado transformaciones sustanciales en las escenas mediáticas y la mayoría de las iniciativas desarrolladas por los Estados, en el caso de haberlas, son más bien esporádicas y de bajo impacto.

Esta escena se registra más allá de la orientación política de los gobiernos. Naciones que han intentado una redistribución de los recursos materiales y simbólicos en los últimos años, como Ecuador y Venezuela, no han avanzado sin embargo en la profundización del combate a las desigualdades de género en la comunicación. Algo similar sucede en Uruguay, donde una coalición política de centro-izquierda no acuerda poner en marcha una nueva regulación de la comunicación que propone la democratización de la escena mediática (Chaher, 2016, p. 18).

\section{Abordaje metodológico}

A nivel metodológico, esta investigación utiliza el análisis de contenidos para la interpretación de los textos (Abela, 2013). El trabajo de análisis de contenidos implicó la sistematización, categorización y análisis de la información. Se hizo énfasis en el sentido directo de los textos, sobre todo, al ser documentos que explicitan acciones, procedimientos y sanciones sobre el uso de los medios de comunicación y la equidad de género. Además, se analizan contenidos de dos

6 Esta investigación retoma los trabajos de Chaher (2014 y 2016), Vega (2009) y la red de investigadoras por la Vida y la Libertad de las Mujeres y las niñas de México (2008), quienes vienen aportando a la reflexión sobre las elaboración de políticas públicas en comunicación con perspectiva de género. 
legislaciones por país: la ley que regula los servicios de radiodifusión sonora y televisiva, y la ley marco de género (Ver Tabla 1). En algunos casos, también se incluyó el reglamento de las leyes de radiodifusión, las leyes en contra de la violencia a las mujeres y/o las leyes de equidad de género (en muchos casos las primeras anteceden a las segundas). En cambio, no se incluyen aquí los servicios de televisión por suscripción o Internet, ni los planes de gobiernos que operativizan la aplicación de las legislaciones.

En el análisis de contenido se identifican y analizan los conceptos de género y derecho a la comunicación, los instrumentos internacionales que usan en estas legislaciones como fuentes de interpretación y las acciones afirmativas relacionadas con la transversalización de género en clave de derecho a la comunicación.

\section{Tabla 1: Leyes incluidas en el análisis}

\begin{tabular}{|c|c|}
\hline País & Leyes incluidas \\
\hline Argentina & $\begin{array}{l}\text { Ley de Servicios de Comunicación Audiovisual, N } 26.522 \text { (2009) } \\
\text { Ley de protección integral para prevenir, sancionar y erradicar la } \\
\text { violencia contra las mujeres en los ámbitos en que desarrollen sus } \\
\text { relaciones interpersonales, No. } 26.485 \text { (2009) }\end{array}$ \\
\hline Bolivia & 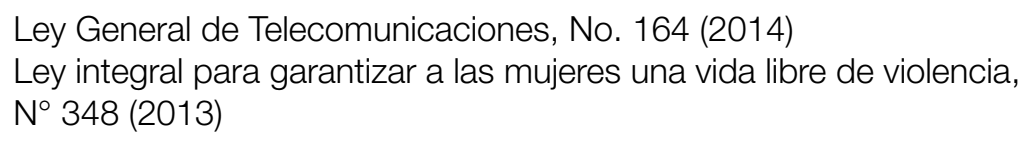 \\
\hline Costa Rica & $\begin{array}{l}\text { Ley de Radio, No. } 1.758 \text { (1954) } \\
\text { Ley General de Telecomunicaciones, No. } 8.642 \text { (2008) } \\
\text { Ley de Promoción de la Igualdad Social de la Mujer, No. } 7.142 \text { (1990) } \\
\text { Ley que Regula Propaganda que Utilice la Imagen de la Mujer, No. } \\
5.811 \text { (1975) } \\
\text { Reglamento a la Ley General de Telecomunicaciones, No. } 34.765\end{array}$ \\
\hline Ecuador & $\begin{array}{l}\text { Ley Orgánica de Comunicación (2013) } \\
\text { Reglamento a la Ley Orgánica de Comunicación (2013) } \\
\text { Ley contra la violencia a la mujer y la familia (1995) }\end{array}$ \\
\hline El Salvador & $\begin{array}{l}\text { Ley General de Telecomunicaciones, No. } 142 \text { (2011) } \\
\text { Ley de Igualdad, Equidad y Erradicación de la Discriminación contra } \\
\text { las Mujeres (2011) }\end{array}$ \\
\hline México & $\begin{array}{l}\text { Ley Federal de Telecomunicaciones y Radiodifusión (2014) } \\
\text { Ley General para la Igualdad entre Mujeres y Hombres (2006) }\end{array}$ \\
\hline Paraguay & Ley de Telecomunicaciones, modificada con la Ley No. 4.179 (2011) \\
\hline Uruguay & $\begin{array}{l}\text { Ley de Servicios de Comunicación Audiovisual, N } 19.307 \text { (2015) } \\
\text { Ley de igualdad de derechos y oportunidades entre hombres y } \\
\text { mujeres en la República, No. } 18.104 \text { (2007) }\end{array}$ \\
\hline
\end{tabular}


Venezuela Ley Orgánica de Telecomunicaciones, No. 39.610 (2011)

Reglamento de la ley orgánica de telecomunicaciones sobre habilitaciones administrativas y concesiones de uso y explotación del espectro radioeléctrico (2011)

Ley de Responsabilidad Social en Radio, Televisión y Medios Electrónicos (2007)

Ley orgánica sobre el derecho de las mujeres a una vida libre de violencia, No. 38.668 (2007)

Fuente: Elaboración propia.

\section{El debate sobre la democratización de las comunicaciones en América Latina}

En los últimos años, asistimos a procesos de discusión sobre las políticas públicas de radiodifusión sonora y televisiva en América Latina. En algunos países ya se han actualizado las legislaciones correspondientes, mientras que en otros apenas se debate sobre el contexto mediático y la necesidad de buscar un nuevo modelo. Estas discusiones se relacionan con la digitalización de la radiodifusión y la amenaza del apagón analógico. También, con las controversias sobre los derechos humanos y la democratización de la información y del conocimiento a través del reconocimiento del derecho a la comunicación.

Asimismo, las

... nuevas regulaciones sobre medios tienen diferentes contextos y orígenes. Algunos procesos se han iniciado en el marco de cambios políticos profundos, expresados en nuevos gobiernos, pero también en la modificación de las propias Constituciones Nacionales que obligan a reformular las normativas secundarias para adecuarlas a los nuevos paradigmas constitucionales. Es el caso de Bolivia y Ecuador (Gómez, 2014, p. 4).

A este paisaje hay que sumar la reforma a la Ley General de Telecomunicación de El Salvador, en la cual se reconocen los medios comunitarios y las medidas por "Decreto de Necesidad y Urgencia", o DNU, que ha tomado el gobierno de Macri en Argentina, el cual modifica la Ley de Servicios Audiovisuales de Argentina. Entre los cambios decretados es factible detectar que se le ha restado independencia al organismo regulador frente al gobierno y que se han reducido o eliminado las limitaciones a la concentración de medios (Gómez, 2016).

Dicho contexto se encuentra relacionado con las discusiones políticas presentes en diversos países de la región. Así, en 2013, algunos sectores se refirieron a los "polémicos proyectos de ley de medios en América Latina" (INFOBAE, 2013), vinculados con los procesos de discusión en Argentina y Uruguay, y en referencia a las leyes aprobadas en Venezuela, Ecuador y Bolivia:

la Sociedad Interamericana de Prensa (SIP) en su último informe condenó las leyes de medios sancionadas en la región que restringen la libertad de prensa 
y declaró su preocupación por las normas impulsadas por los gobiernos de Venezuela, Ecuador y Argentina, a quienes llamó a descomprimir las tensiones con la prensa (INFOBAE, 2013).

En síntesis, han sido diversos flujos los que han incidido en que los países cambien sus legislaciones de medios, las propias constituciones, las nuevas tecnologías digitales para el uso del espectro radioeléctrico, los debates sobre los modelos políticos y de gobierno en América Latina, y la presión desde el reconocimiento y democratización del derecho a la comunicación.

\section{Los diversos contextos nacionales}

En Bolivia, Ecuador y Venezuela, las modificaciones en las legislaciones de medios pasan por cambios en las políticas de Estado y en la elaboración de nuevas constituciones nacionales. Según datos del OBSERVACOM (2016), la regulación en materia de medios de comunicación audiovisual en Venezuela está establecida en la Ley Orgánica de Telecomunicaciones de 2000, la Ley de Responsabilidad Social en Radio, Televisión y Medios Electrónicos de 2004 y en diversos reglamentos para la radiodifusión comunitaria, la operación de las estaciones de radiodifusión sonora y el reglamento para el control de las concesiones de televisión. La Ley Orgánica de Telecomunicaciones de 2000 fue pionera en temas como la democratización de los medios y el reconocimiento de los medios comunitarios. Por su parte, la Ley de Responsabilidad Social en Radio, Televisión y Medios Electrónicos puso énfasis en el uso de los medios para el fortalecimiento de la identidad, soberanía y seguridad de la nación, así como de la producción nacional de contenidos. La Ley de Responsabilidad Social ha sido celebrada, ya que moderniza la estructura de las comunicaciones, mientras que sus detractores indican que supone un intento de hacerse del control de los medios privados de difusión (Artículo 19, 2011). Desde la perspectiva de género, existe la Ley Orgánica sobre el Derecho de las Mujeres a una Vida Libre de Violencia, aunque existe un proyecto de Ley Orgánica para la Equidad e Igualdad de Género que aún no ha sido aprobado.

El marco regulatorio al que hemos hecho referencia no incorporó dimensiones de género, con lo cual quedaron desatendidos importantes aspectos relacionados con el área de mujeres y medios de comunicación como el uso de estereotipos de género y la publicidad sexista entre otros. Más aún, no existen políticas públicas o lineamientos relacionados con el ámbito de mujeres y medios de comunicación. La temática ha sido abordada solamente desde el terreno de la violencia contra la mujer, mediante la tipificación de la violencia mediática en el texto de la Ley Orgánica sobre el Derecho de las Mujeres a una Vida Libre de Violencia (en adelante Ley de Violencia), aprobada en el año 2007 (Kislinger, citado por Chaher, p. 147).

En julio de 2014 se creó el Observatorio de Medios Carmen Clemente Travieso, dependiente del Instituto Nacional para la Mujer (INAMUJER), de Venezuela. Dicha instancia tiene el propósito de dar seguimiento a contenidos discriminatorios, en cumplimiento de los artículos sobre violencia mediática y violencia simbólica de la Ley Orgánica sobre el Derecho de las Mujeres a una Vida Libre 
de Violencia. Este conjunto de instancias ha tenido especialmente un enfoque punitivo. Así, el hecho de estar adscritas a un ente gubernamental genera dudas sobre su independencia de criterio, imparcialidad y continuidad.

Desde el sector gubernamental, se percibe voluntad política para incluir la perspectiva de género en el discurso oficial. La violencia mediática, como temática, ha sido incluida en algunas iniciativas de capacitación y divulgación poco sostenidas en el tiempo, por lo que el Comité para la Eliminación de la Discriminación contra la Mujer (CEDAW), en sus observaciones, pidió al Estado venezolano monitorear la imagen de la mujer en los medios de comunicación, en el Internet, así como en las declaraciones del funcionariado público (Kislinger, en Chaher, p. 148).

Rocha (citado por Chaher, 2016) explica que, en Bolivia, la discusión durante los últimos diez años presentó tres características principales: "las iniciativas legislativas sobre temas comunicacionales han sido propuestas ... desde sectores sociales" (p. 49); la posición del gremio periodístico no ha sido unánime en distintas ocasiones y "el gobierno nacional no ha mencionado en ningún momento la voluntad de impulsar una ley de tipo integral" (p. 50), sino que han aprobado reformas sectoriales. En 2009, se logró estipular el derecho a la información y comunicación dentro de la nueva Constitución Política (Rocha, citado por Chaher, 2016, p. 50). En la nueva Carta Magna, se prohíbe la formación de monopolios y oligopolios en los medios de comunicación social, y se reconoce el derecho a la creación de medios de comunicación comunitarios en igualdad de condiciones y oportunidades (Gomez, 2014, p. 16). Posteriormente, se desarrollaron una serie de legislaciones que provocaron protestas entre el gremio de la comunicación, por ejemplo, en la formulación del proyecto de Ley de Telecomunicaciones y Tecnologías de Información y Comunicación, "referido a Mensaje Presidenciales Oficiales, y que obliga a los medios de comunicación a transmitirlos en dos fechas determinadas haciendo cadena nacional" (Rocha, citado por Chaher, 2016, p. 53).

La Ley No.164 General de Telecomunicaciones, Tecnologías de Información y Comunicación fue aprobada en 2011 y, su posterior reglamentación, a través del Decreto Supremo №1391 en 2012. Esta "fue la primera experiencia en el país en haber abierto una plataforma web y haber utilizado redes sociales digitales para alimentar su debate" (Rocha, citado por Chaher, 2016, p. 53). El gobierno del presidente Evo Morales ha sido fuertemente criticado por la aprobación de esta ley, debido a que se reserva un 33\% del espectro para el Estado y un 17\% para los pueblos indígenas, grupos en los que posee una importante cuota de poder, con lo cual, se le acusa de controlar un gran porcentaje de los medios. Como respuesta, Morales ha declarado que es uno de los primeros y más importantes pasos para descolonizar el país.

Respecto a las leyes de género, Rocha (2016) señala que "las medidas para generar un marco específico para las mujeres estuvieron por mucho tiempo 
gestándose, bajo el abrigo del mandato constitucional" (p. 57); no obstante, fue la coyuntura la que logró consolidarlas. La Ley para Garantizar a las Mujeres una Vida Libre de Violencia de 2013 fue promulgada "después del feminicidio de la periodista Hanalí Huaycho" (p. 58).

\section{En Ecuador, la Ley de Comunicación aprobada en 2013}

incluye tanto a los medios audiovisuales como a la prensa escrita. Tiene un fuerte componente de regulación de contenidos de los medios, aunque también disposiciones referidas a la gestión del espectro radioeléctrico, procedimientos de acceso a concesiones, así como limitaciones a la formación de monopolios y oligopolios (Gómez, 2014, p. 25).

Esta Ley que surgió de una "consulta popular y ha sido defendida por el presidente Correa como un freno a los abusos de los medios privados, a los que suele identificar como su mayor opositor" (Diario de Cuba, 2015), fijó una nueva distribución de frecuencias de radio y televisión entre sectores privados, públicos y comunitarios y aumentó los controles sobre la prensa. Al 2015, la Superintendencia de la Comunicación (el órgano de control) sancionó "a 198 medios, ha realizado 506 procesos y ha generado 313 resoluciones, de las que 185 han sido sanciones económicas, con las que el Estado ha recaudado 201.596 dólares" (Constante, 2015).

la Ley Orgánica de Comunicación (LOC), que no incluye disposiciones sobre género, sólo sobre discriminación y violencia en general. Tampoco hay otra normativa que refiera a comunicación y género en el país. La aplicación de la LOC tampoco ha sido generosa en la regulación en torno a la discriminación, sino que la mayoría de las denuncias (mayormente de oficio o realizadas por el funcionariado público) fueron iniciadas por vulneración del derecho a la honra y en nombre del derecho a réplica y rectificación, lo cual le ha valido a la norma, tanto en la escena nacional como internacional, el llamado de atención por la afectación de la libertad de expresión (López, citado por Chaher, 2016, p. 90).

En junio del 2016 la LOC fue cuestionada por el Comité de Derechos Humanos de la Organización de Naciones Unidas (ONU) que manifestó preocupación por algunas disposiciones que podrían afectar el ejercicio de libertad de expresión, así como por las amenazas que reciben las personas que critican al gobierno y el uso excesivo de su fuerza (OBSERVACOM, 2016).

Los casos de Argentina y Uruguay son similares en varios sentidos; estos reconocen los medios comunitarios, se aprobaron con el apoyo de un movimiento social y una voluntad política de los gobiernos de ese momento (antes de los decretos del gobierno de Macri en Argentina). Además, casi no abordan regulaciones que afecten la programación de los medios en relación con sus actividades informativas o periodísticas, a no ser para proteger los derechos de la niñez o de las personas consumidoras, y promover la producción de contenidos de origen nacional frente a la extranjera (Gómez, 2014, p. 7). El Senado de Argentina aprobó la Ley No. 26.522 de Servicios de Comunicación Audiovisual el 10 de octubre de 2009. Esta fue presentada por la entonces presidente 
Cristina Fernández de Kirchner, a partir de un proceso de creación, debate y análisis ciudadano, y vino a reemplazar la legislación que se estableció en los años ochenta, durante la dictadura. También, en 2009, se aprobó la Ley No. 26.485 de Protección Integral de la Violencia Hacia las Mujeres; según Chaher (2016), ambas promulgaciones "se enmarcar en un proceso de ampliación de derechos sociales y políticos del gobierno que asumió el poder en 2003". La autora señala que esta legislación es el "resultado del consenso en base a diversos proyectos que expresaban el anhelo del movimiento de mujeres porque el país contara con una ley actualizada sobre el tema" (p. 27). Chaher (2016), parafraseando a Vega Montiel (2014), apunta que, con ambas normas, se posibilitó la creación de un marco normativo de políticas blandas y duras. "El Estado argentino desarrolló en los años siguientes una política pública de comunicación y género que fue vanguardia para la región" (p. 31).

Con la llegada al poder de la coalición Cambiemos, entre diciembre de 2015 y enero de 2016, "el nuevo gobierno modificó sustancialmente el escenario de las comunicaciones en Argentina con tres decretos presidenciales". Los cambios modificaron "la estructura de los organismos de control del sector de las comunicaciones; y eliminar los artículos de la ley que limitaban la propiedad de los medios" (Chaher, 2016, p. 36). Si bien la autora admite que las medidas del nuevo gobierno no afectaron lo relacionado con comunicación y género, "las disposiciones que promueven la concentración de la propiedad de los medios tienen inevitablemente consecuencias sobre la pluralidad de voces" (p. 38).

Desde 2016, la Comisión para la Elaboración del Proyecto de Reforma, Actualización y Unificación de las Leyes 26.522 y 27.078 trabajan con empresas, personas trabajadoras de medios y personas usuarias para la creación de un nuevo proyecto de comunicaciones (Chaher, 2016, pp. 31-32).

En Uruguay, el Poder Ejecutivo aprobó en el año 2014, la Ley No. 19.307 de Servicios de Comunicación Audiovisual, también como Ley de Medios. Aunque esta ley ha contado desde el primer momento con el respaldo de las organizaciones de la sociedad civil, la academia y reconocidas voces del ámbito internacional, como los relatores de Libertad de Expresión de la OEA, la ONU, el Comité para la Protección de Periodistas (CPJ), Reporteros sin Fronteras y UNESCO (Celiberti, en Chaher 2016, p. 142). Además, el ranking "Clasificación Mundial de la Libertad de Prensa 2016" de la organización internacional Reporteros Sin Fronteras (RSF) colocó a este país -gracias a la ley- en el primer lugar de América del Sur y en el puesto 20 del mundo.

La ley no ha recibido mucha aceptación por parte de algunos sectores del país, por lo que se han presentado 28 acciones de inconstitucionalidad y una solicitud de inconstitucionalidad por vía de la excepción ante la Suprema Corte Uruguaya, que "falló en la mayoría de los casos sin que lo fundamental de la ley se haya visto afectado" (Viggiano, 2017, párr. 1). Tuvo, además, 
la decidida oposición por parte de las empresas de comunicación que impugnaron por inconstitucional alrededor de 60 artículos de la Ley (Celiberti, citado por Chaher 2016, p. 145).

Desde su aprobación el Poder Ejecutivo no la ha reglamentado. Se argumenta que la norma ha recibido impugnaciones en el Poder Judicial. Un aspecto positivo es que dentro de los casos ya resueltos por la Corte Suprema de Justicia ha sido declarado constitucional el articulado vinculado a discriminación (Celiberti, citado por Chaher, 2016, p. 131). El "Proyecto de ley integral para garantizar a las mujeres una vida libre de violencia basada en género", el cual incluye una definición de la violencia simbólica y violencia mediática, fue presentado por el Instituto Nacional de las Mujeres del Ministerio de Desarrollo Social y remitido por el Poder Ejecutivo al Poder Legislativo, actualmente se encuentra a estudio de la Comisión de Población, Desarrollo e Inclusión de la Cámara de Senadores (Cámara de Senadores, 2016).

En el caso de Paraguay, rige la Ley No. 642 de Telecomunicaciones del año 1995, aprobada por la Cámara de Senadores y la de Diputados, y el Decreto $N^{\circ} 14.135$ de 1996 que la reglamenta. Es una Ley que "regula los llamados servicios de difusión (dentro de los cuales están la radiodifusión sonora y la televisión) y existe un capítulo destinado a regular los servicios de radiodifusión de pequeña y mediana cobertura o radios comunitarias" (Gómez, 2014, p. 36). Varios de sus artículos han tenido modificaciones y ampliaciones en los años 2004 y 2011. Actualmente la Comisión Nacional de Telecomunicaciones (CONATEL) busca realizar nuevos cambios. La ley vigente, aunque reconoce un lugar para los medios comunitarios, los ubica a pequeña y mediana escala, y no explicita referencias al reconocimiento del derecho a la comunicación. El 10 de agosto de 2017 se presentó ante la Cámara de Senadores en Paraguay un proyecto de Ley para el sector audiovisual, el cual busca darle un impulso a este sector en el país. Entre los principales puntos de este proyecto destaca la creación del Instituto Nacional del Audiovisual Paraguayo (INAP), así como del Fondo Nacional del Audiovisual (Fonap). "El Instituto brindará garantías institucionales para que haya oportunidades para toda la gente que quiera dedicarse al audiovisual y que ya se está dedicando hoy al audiovisual", indicó Ricardo Arriola, integrante de la Cámara Paraguaya de Empresas Productoras de Cine y Televisión (Campro). Se espera que el proyecto se apruebe en los próximos días (Última hora, 2017).

En Centroamérica, se presenta la situación más difícil de la región. En los casos de Costa Rica y El Salvador se puede observar la vigencia de legislación desactualizada frente a los cambios tecnológicos de la radiodifusión y el reconocimiento del derecho a la comunicación. De acuerdo con la Ley General de Telecomunicaciones No 8.642 del 2008, en Costa Rica, el otorgamiento de concesiones y la prestación de los servicios de radiodifusión y televisión se rige por lo dispuesto en la Ley de radio, No. 1.758, del 19 de junio de 1954, documento con una normativa obsoleta y con diversos vacíos, en donde 
no se contemplan los compromisos internacionales asumidos por el país para garantizar la diversidad de voces necesaria en los países democráticos, así como con los avances tecnológicos, que se concretan con la transición a televisión digital que debería darse finalizando el 2017 (Carazo y Ochoa, 2016, p. 1).

Desde el año 2008, diversas instancias han manifestado la necesidad de renovar la legislación de medios en Costa Rica: Contralaría General de la República, Superintendencia de Telecomunicaciones (SUTEL), universidades públicas $^{7}$, organizaciones sociales como la Red de Medios e Iniciativas de Comunicación Alternativos (RedMICA), entre otros sectores. Pese a ello, los sectores empresariales señalan que no hace falta una ley de televisión que regule el espacio radioeléctrico digital (Soto, 2017); desde esta perspectiva, la mejor ley es la que no existe. Actualmente, hay dos propuestas de ley: por una parte, la Ley Participativa de Radio y Televisión generada desde los movimientos sociales y medios alternativos, la cual está en proceso de recolección de 160000 firmas para lograr llevar el documento a la Asamblea Legislativa por iniciativa popular. El movimiento, en formación, incluye comunicadores, docentes, estudiantes, activistas, profesionales del derecho, entre otros; y busca democratizar el uso del espectro radioeléctrico en pro del derecho a la comunicación de las y los ciudadanos (RedMICA, 2015, Artículo 10).

Además, frente a la urgencia de una nueva legislación a las puertas del apagón analógico previsto para finales de 2017, diputados y diputadas de diversas bancadas políticas han presentado un proyecto de ley que "garantiza que las frecuencias repetidoras sean recuperadas por el Estado para montar una nueva red de canales públicos y privados. De esta forma, 38 frecuencias que podrían transmitir hasta 152 canales no quedarían en unos pocos empresarios" (Soto, 2017).

En El Salvador, la regulación de los medios de comunicación audiovisuales se basa en la Ley de Telecomunicaciones de 1997 y su reglamento, aprobado en 2011. En este país, la legislación establece que el espectro pertenece al Estado y es un bien privado de los concesionarios durante el periodo de concesión. La distribución de las concesiones de frecuencias se ha realizado mediante una subasta económica, privilegiando la capacidad económica (Gomez, 2014, p. 28). La Sala Constitucional de la Corte Suprema de Justicia (CSJ) ordenó la inclusión de reformas a la Ley ${ }^{8}$. En 2016, se aprobó una reforma ${ }^{9}$ muy

7 Se destaca el Programa de Libertad de Expresión, Derecho a la Información y Opinión Pública (PROLEDI) de la Universidad de Costa Rica y OndaUNED de la Universidad Estatal a Distancia.

8 El proceso de reforma inició en el 2012 cuando organizaciones como la Asociación de Radios y Programas Participativos (ARPAS) y Red por el Derecho a la Comunicación (ReDCo) hicieron demandas de inconstitucionalidad contra la Ley de Telecomunicaciones, que es una "ley excluyente. Se hizo solo con una visión empresarial y se dejó de lado las otras visiones que tienen que ver con que existan medios públicos y la visión de la comunicación como un derecho colectivo de los grupos organizados de la sociedad a tener medios de comunicación; medios sociales comunitarios sin fines de lucro" Entrevista a Leonel Herrera de ARPAS por Vargas (2016).

Esta reforma no se incluye en el análisis, pues fue realizada en una fase avanzada de la investigación. 
importante, porque "reconoce al sector de radios comunitarias y con fines sociales. También modificó las disposiciones que aseguraban licencias eternas e incluyó mecanismos de concursos para el acceso a frecuencias" (OBSERVACOM, 2016). Además, "actualiza el pago de una tasa anual por el uso de las frecuencias, a excepción de los medios sin ánimo de lucro, quienes estarán exentos del pago" (OBSERVACOM, 9 de mayo de 2016). El 25 de noviembre de 2010 se aprobó la Ley Especial Integral para una Vida Libre de Violencia para las Mujeres, que entró en vigencia en 2012 (Cidón, 2016, p. 111). Cidón apunta que a cinco años de estar vigente "se ha observado que los medios del Estado y aquellos que reciben subvenciones, sí aplican el enfoque de género, el lenguajes inclusivo y difunden las campañas del gobierno que promueven la igualdad sustantiva" (p. 113).

Finalmente, México es un caso especial porque la ley de telecomunicaciones ha sufrido muchas modificaciones entre las que destaca la llamada "Ley Televisa" del 2006, la cual "implicó importantes cambios a la normativa sobre medios. Sin embargo, una sentencia de la Suprema Corte de Justicia en 2007 derogó total o parcialmente varias de las disposiciones de la ley por lo cual quedaron varios vacíos jurídicos" (Gomez, 2014, p. 32). La última modificación fue la Reforma de telecomunicaciones de 2014, en México. Se trata de una reforma constitucional presentada por Enrique Peña Nieto, presidente de la República. Esta ha recibido grandes críticas por diversos sectores, principalmente por brindar más protección y poder al monopolio de las grandes empresas de radiodifusión del país.

En efecto, es una ley con un enfoque hacia la protección de los medios y empresas de comunicación. No obstante, las últimas modificaciones también han generado cambios positivos pues "la legislación mexicana sobre medios audiovisuales hasta el momento no reconocía a los medios comunitarios, pero la nueva ley ha aprobado el reconocimiento expreso de un sector de medios sociales, dentro del cual se encuentran las emisoras comunitarias e indígenas" (Gómez, 2014, p. 34). En febrero de 2017, Peña Nieto impugnó 8 artículos de la Ley Federal de Telecomunicaciones y Radiodifusión, así como de los Lineamientos Generales sobre el Derechos de las Audiencias. Esto ya que, según el mandatario, invaden competencias del poder ejecutivo. Estos artículos están relacionados principalmente con competencias del Instituto Federal de Telecomunicaciones, y con el derecho de las audiencias con discapacidad (Milenio Digital, 2017). 


\section{Definiciones: cómo se entiende el género y el derecho a la comunicación}

El primer eje de análisis sobre la transversalización del derecho a la comunicación y la perspectiva de género ${ }^{10}$ en las legislaciones de los nueve países estudiados se vincula con la incorporación de una referencia explícita a la equidad o igualdad de género y al derecho a la comunicación.

Tabla 2: Países y definiciones conceptuales

\begin{tabular}{|ccc|}
\hline Concepto & Derecho a la comunicación & Género \\
\hline \multirow{2}{*}{ Lo incorporan } & Argentina & Argentina \\
& Bolivia & Bolivia \\
Ecuador & Ecuador \\
Paraguay & Paraguay \\
Uruguay & El Salvador \\
Venezuela & México \\
& & Venezuela \\
No lo incorporan & & \\
& Costa Rica & Costa Rica \\
& El Salvador & Uruguay \\
& México & \\
\hline
\end{tabular}

Fuente: Elaboración propia.

\section{Derecho a la comunicación}

El derecho a la comunicación se entiende de formas diversas en cada ley, en algunos casos se reconoce de forma explícita y en otros no. En términos generales, las leyes hablan del derecho de toda persona, individual o colectivo, de recibir, emitir e investigar informaciones, ideas y opiniones. Las apariciones del derecho a la comunicación de manera explícita se dan únicamente en las leyes de servicios de comunicación o telecomunicaciones de Ecuador (Artículo 16), Bolivia (Artículo 1), Uruguay (Artículo 5) y Venezuela (Artículo 1). En las leyes de radiodifusión y telecomunicaciones de Bolivia, Ecuador y Uruguay se enfatiza el fomento y visibilización de la diversidad económica, social, política y principalmente cultural; se habla de una comunicación libre, participativa y diversa. Ecuador rescata que el derecho pueda ser ejercido por cada persona en su propia lengua y símbolos, mientras que Venezuela defiende la libertad

10 Aunque perspectiva de género, equidad o igualdad de género no son lo mismo, en el análisis de contenido se usaron los tres términos para ampliar las posibilidades de valorar si existía algún tipo de enfoque de género incorporado. 
para actividades económicas de telecomunicaciones. El Salvador defiende los derechos de los usuarios, puesto en masculino el término usuario, en áreas como el acceso a la telefonía, a comunicaciones sin interferencias, a "que no se le desconecte arbitrariamente el servicio" (Artículo 29). La ley de Costa Rica se presenta en los mismos términos, habla de un derecho del usuario al acceso a un servicio de telecomunicaciones (Artículo 6).

México es el único país que enfatiza que esta libertad "no será objeto de ninguna persecución o investigación judicial o administrativa, ni de limitación alguna ni censura previa" (Artículo 22). Por ello consideramos que estos tres países no abordan el concepto del derecho a la comunicación, como ha sido definido desde el mismo enfoque que se explicita en al apartado de marco conceptual. En todos los países existe un reconocimiento básico de medios comerciales y medios no comerciales (o con o sin fines de lucro) que tienen, a su vez, distintas denominaciones y categorías. Los medios comunitarios son reconocidos en Ecuador, Argentina, Venezuela, Bolivia, Uruguay y, más recientemente, en El Salvador. La Ley No. 26.522 de Servicios de Comunicación Audiovisual de Argentina era la más desarrollada, ya que incluso plantea medios universitarios, educativos y de pueblos originarios. Bolivia también dedica un $33 \%$ de su espectro a medios para comunidades, $17 \%$ de ellos para grupos indígenas. México reconoce medios de comunicación para uso social, dentro de los cuales destacan los medios comunitarios y los destinados a universidades.

\section{Género}

En las leyes marco de género de los países estudiados existe problematización y algunos conceptos relacionados con la perspectiva o equidad de género. Sin embargo, las perspectivas son muy limitadas y se concentran principalmente en el trato desigual hacia las mujeres. Solo en México, mediante la Ley General para la igualdad entre mujeres y hombres, se define la perspectiva de género como "la metodología y los mecanismos que permiten identificar, cuestionar y valorar la discriminación, desigualdad y exclusión de las mujeres" (Artículo 6).

Los países que tienen leyes basadas en erradicar la violencia contra las mujeres son Argentina, Bolivia, Ecuador, Venezuela; además de estas leyes, se identificaron en Paraguay y Ecuador planes o agendas nacionales para abordar la igualdad de género. Por su parte, El Salvador, México y Uruguay tienen leyes de igualdad de derechos y oportunidades de las mujeres.

En Ecuador, la Ley contra la violencia de la mujer no indica de forma explícita el tema de género, solo considera la violencia dentro del núcleo familiar; sin embargo, más allá de la ley, existe la Agenda Nacional de las Mujeres y la Igualdad de Género 2014-2017, la cual discute la perspectiva de género desde el tema de las desigualdades. Asimismo, esta política pública ecuatoriana sobresale por hacer distinción entre igualdad formal (la que se establece 
en el marco jurídico) e igualdad sustantiva (la que garantiza verdaderamente el disfrute de los derechos humanos) y por el sistema de comunicación con respecto a la "difusión de contenidos y mensajes machistas, sexistas, misóginos, o que promuevan la violencia de género" (Consejo Nacional de Igualdad de Género, 2015, p. 77); y el "fomento de la producción cultural, comunicacional y artística desde el principio de igualdad y no discriminación con el fin de transformar patrones socioculturales ... que reproducen estereotipos de género, violencia basada en género y la división sexual del trabajo" (Consejo Nacional de Igualdad de Género, 2015, p. 52).

La Ley 348 de Bolivia aborda los conceptos de "equidad de género" y es el único país que habla sobre patriarcado, o más bien, sobre despatriarcalización, como la elaboración de políticas públicas desde la identidad plurinacional, para la visibilización, denuncia y erradicación del patriarcado, a través de la transformación de las estructuras, relaciones, tradiciones, costumbres y comportamientos desiguales de poder, dominio, exclusión opresión y explotación de las mujeres por los hombres (Artículo 4). Por su parte, la Ley 26.486 de Argentina define "sexismo", "violencia contra las mujeres" y "relación desigual de poder", además aboga por "la remoción de patrones socioculturales que promueven y sostienen la desigualdad de género y las relaciones de poder sobre las mujeres" (Artículo 2, Inciso e). En la misma línea, El Salvador habla respecto al principio de igualdad real entre hombres y mujeres.

En Costa Rica hay varias leyes que abordan el tema, la Ley de Promoción de la lgualdad Social de la Mujer No 7.142 (1990), Ley 5.811 que Regula Propaganda que Utilice la Imagen de la Mujer de 1998, y la Ley $N^{\circ} 8.589$ de Penalización de la Violencia contra las Mujeres de 1995. La Ley $N^{\circ} 7.142$, aunque sí propone medidas por ejemplo en ámbitos de educación ${ }^{11}$, no da pautas en el ámbito de las comunicaciones, omitiendo su importancia en los procesos de socialización de las nuevas generaciones.

En Uruguay la Ley $N^{\circ} 18.104$ de igualdad de derechos y oportunidades entre hombres y mujeres declara de interés general las actividades orientadas a la igualdad de derechos y oportunidades entre hombres y mujeres en la República de Uruguay, y encomienda al Instituto Nacional de las Mujeres el diseño del Plan Nacional de Igualdad de Oportunidades y Derechos para dar cumplimiento a los instrumentos ratificados o firmados en el ámbito internacional. En esta ley no se encontró referencia al tratamiento de género, la Ley No. 18.620 de derecho a la identidad de género y al cambio de nombre y sexo en documentos identificatorios, y hay un proyecto de Ley para garantizar a la

11 Artículo 17. Están prohibidos en cualquier institución educativa nacional todos los contenidos, métodos o instrumentos pedagógicos en que se asignen papeles en la sociedad a hombres y mujeres contrarios a la igualdad social y a la complementariedad de los géneros, o que mantengan una condición subalterna para la mujer (Ley No. 7.142 de promoción de la igualdad social de la mujer, Asamblea Legislativa de la República de Costa Rica, 1990). 
mujeres una vida libre de violencia basada en género (11 de abril de 2016) que aún está en discusión.

En México, la Ley General para la Igualdad entre Mujeres y Hombres, hace un llamado a velar por que los medios de comunicación transmitan una imagen igualitaria plural y no estereotipada en la sociedad, promuevan el conocimiento y la difusión del principio de igualdad entre mujeres y hombres y eviten la utilización sexista del lenguaje (Artículo 42).

La violencia mediática es un tema común en las legislaciones de Argentina, Bolivia, Venezuela, Paraguay y El Salvador. La Ley de protección integral a las mujeres, de Paraguay, define de manera específica no solo violencia mediática, sino también violencia telemática y simbólica. En general se habla de evitar el uso de la imagen de la mujer para fines que promuevan la desigualdad, violencia, estereotipos, fines pornográficos; cada país sanciona la discriminación, especialmente en la publicidad.

La utilización de lenguaje inclusivo está ausente en la mayoría de las legislaciones de telecomunicaciones de los países, y ni siquiera se menciona. A modo de excepción destaca Bolivia, que utiliza en algún grado este tipo de lenguaje. En las políticas públicas de género si se usan en gran parte de los países, aunque inconsistentemente. Destaca la Ley de Igualdad, Equidad y Erradicación de la Discriminación contra las Mujeres, de El Salvador, que solo lo utiliza lenguaje, sino que además tiene todo un artículo dedicado a este tema y llamado "Erradicación del Sexismo en el Lenguaje Institucional y Social" (Artículo 15).

\section{Transversalización del derecho a la comunicación con perspectiva de género}

En el siguiente apartado se analizan los nueve casos estudiados en relación con sus avances en la transversalización del derecho a la comunicación con perspectiva de género. Se hace un esfuerzo por destacar las medidas tomadas para favorecer su cumplimiento y los rezagos que hay en algunos países con respecto a aquellos que están más avanzados. 
Tabla 3: Clasificación de los países según avances de transversalización

\begin{tabular}{cc} 
Leyes & Países \\
\hline Más avanzadas & Argentina \\
& Bolivia \\
& Ecuador \\
& Paraguay \\
Intermedias & Uruguay \\
& Venezuela \\
Rezagadas & México \\
& Costa Rica \\
\hline
\end{tabular}

Fuente: Elaboración propia.

\section{Las más completas}

Las legislaciones de estos países se ubicaron en el nivel más alto de acuerdo a la forma como se entienden, construyen y transversalizan el derecho a la comunicación y el género. Se contempla no solo que los incluyan, sino que creen las medidas pertinentes para garantizar que los derechos ciudadanos sean efectivos y que se transforme la forma como los medios crean y perpetúan la discriminación por motivo de género.

En Argentina, la Ley 26.522 de Servicios de Comunicación define la violencia simbólica (Artículo 5) y plantea que el objetivo principal de los servicios audiovisuales es promover "la diversidad, el acceso universal y la participación en igualdad de oportunidades para todas y todos los habitantes de la Nación" (Artículo 2). También, establece que el derecho para acceder a la información no puede limitarse por razones de etnia, género, orientación sexual, ideología, situación socioeconómica o nacionalidad. Consecuentemente, la Ley 26.485 para erradicar la violencia contra las mujeres define la violencia mediática y establece la realización permanente de mensajes y campañas de sensibilización y concientización para la población, que promueva en los medios masivos el respeto por los derechos humanos de las mujeres, el tratamiento de la violencia desde la perspectiva de género y la eliminación del sexismo en la información (Artículo 9).

En Bolivia, la Ley General de Telecomunicaciones y la Ley 348 para una vida libre de violencia integran el derecho a la comunicación de todas y todos los ciudadanos de la nación, haciendo énfasis en los pueblos originarios y el 
campesinado. Además, incluye el diseño e implementación de una estrategia nacional de comunicación, que incluya campañas en medios masivos dirigidas a informar y a sensibilizar sobre las causas, formas y consecuencias de la violencia contra las mujeres. Estas persiguen, de igual modo, desestructurar estereotipos patriarcales de subordinación y desvalorización de las mujeres, considerando la diversidad cultural y destinando para dicho fin los mismos recursos que asigna a la publicidad sobre temas estratégicos para el desarrollo nacional (Ley 348, Artículo 22).

En la Ley 348 también se define la violencia mediática (Artículo 7) y se establece que, mediante Políticas Sectoriales, el Estado Central y las Entidades Territoriales Autónomas deberán articularse para adoptar medidas para erradicar toda forma de violencia contra las mujeres. En el caso de los medios, "para deconstruir los estereotipos sexistas y los roles asignados socialmente a las mujeres ... promoviendo la autorregulación de la publicidad y el uso irrespetuoso y comercial de la imagen de las mujeres" (Ley 348, Artículo 14).

En Ecuador, se establece que "el sistema de comunicación social debe asegurar el ejercicio de los derechos a la comunicación, la información y la libertad de expresión y fortalecer la participación ciudadana" (Asamblea Nacional República del Ecuador, 2013, p. 3). Además, propone mecanismos para el ejercicio del derecho a la comunicación con especial atención en pueblos indígenas. La Ley Orgánica de Comunicación ecuatoriana ha sido reconocida porque no solo regula la distribución del espectro radioeléctrico sino también los contenidos. En lo que respecta a esta investigación destaca la prohibición de contenidos discriminatorios que realicen distinción, exclusión o restricción basada en diversas razones, entre ellas el sexo, la identidad de género y la orientación sexual (Arts. 60 y 61).

Por su parte, la Ley contra la violencia de la mujer y la familia no reconoce la violencia simbólica o mediática y solamente tiene por ámbito de aplicación a miembros del núcleo familiar hasta el segundo grado de afinidad (Artículo 3). Desde el año 2010, está la propuesta de Proyecto de Ley de igualdad entre las Mujeres y Hombres y Personas de Diversa Condición Sexo Genérica. En el Informe sobre la Aplicación de la Declaración y la Plataforma de Acción Beijing se indica que en Ecuador está pendiente terminar la reforma legal para incluir el género en las leyes expedidas por la ensamblada nacional.

En el caso de Paraguay, la Ley de Telecomunicaciones se articula con la de protección integral a las Mujeres contra toda forma de violencia. Esta segunda Ley tiene un acercamiento a la transversalización del derecho a la comunicación y perspectiva de género, pues además otorga deberes específicos a la Secretaría de Comunicación e Información, con respecto a detener la violencia en contra de las mujeres: prevención de violencia, campañas de sensibilización y otros. También hay un apartado relacionado con la capacitación a profesionales de comunicación en esta materia. Asimismo, si bien este artículo explora 
únicamente leyes de género y comunicación, no se puede dejar de mencionar el III Plan Nacional de igualdad de oportunidades entre hombres y mujeres 2008-2017, que es uno de los mejores ejemplos de una adecuada y oportuna transversalización en política pública.

\section{Las leyes intermedias}

Las leyes intermedias se ubican en Venezuela, Uruguay y México. Si bien estas incluyen medidas de prohibición de contenidos que promueven la discriminación por género y -en algunos casos- la definición de la violencia mediática y simbólica, se quedan a medio camino en el proceso de transversalización del género y el reconocimiento del derecho a la comunicación de las mujeres. En Venezuela, por ejemplo, la Ley Orgánica de Telecomunicaciones (Asamblea Nacional Constituyente, 2011) en su artículo 2 establece que uno de sus objetivos es "promover y coadyuvar el ejercicio del derecho de las personas a establecer medios de radiodifusión sonora y televisión abierta comunitarias de servicio público sin fines de lucro, para el ejercicio del derecho a la comunicación libre y plural” (p. 1).

En el caso de la Ley de Responsabilidad Social en Radio, Televisión y Medios Electrónicos (Asamblea Nacional de la República Bolivariana de Venezuela, 2011) se hace un llamado a "procurar que la difusión de información y materiales dirigidos a los niños, niñas y adolescentes formen una adecuada conciencia sobre la igualdad de los sexos" (Artículo 4). Además, prohíbe la difusión de mensajes que inciten el odio o la intolerancia, en la radio, televisión y medios electrónicos, incluyendo por motivos de género (Artículo 28).

Por su parte, en la Ley Orgánica sobre el Derecho de las Mujeres a una Vida Libre de Violencia (Asamblea Nacional de la República Bolivariana de Venezuela, 2007) se define la violencia mediática y la violencia simbólica. La primera se entiende como "la exposición, a través de cualquier medio de difusión, de la mujer, niña o adolescente, que de manera directa o indirecta explote, discrimine, deshonre, humille o que atente contra su dignidad con fines económicos, sociales o de dominación" (Artículo 15). El segundo tipo de violencia remite a "los mensajes, valores, iconos, signos que transmiten y reproducen relaciones de dominación, desigualdad y discriminación en las relaciones sociales que se establecen entre las personas y naturalizan la subordinación de la mujer en la sociedad" (Asamblea Nacional de la República Bolivariana de Venezuela, 2007, Artículo 15). En su artículo 28 se promueve la producción de programas destinados a prevenir y eliminar la violencia contra las mujeres en las programaciones de los medios de difusión masiva. Avala el establecimiento de cuotas de tiempo mínimo para la transmisión de mensajes en contra de la violencia de género y para la promoción de valores de igualdad en las emisoras radiales y televisivas. 
En Uruguay, la Ley No. 19.307 de Servicios de Comunicación Audiovisual (2014) sostiene que la naturaleza de los medios es ser "portadores de informaciones, opiniones, ideas, identidades, valores y significados" (Senado y la Cámara de Representantes de la República Oriental del Uruguay, 2014, Artículo 5) y que no deben ser para fines meramente comerciales. Reconoce el derecho a comunicar y a recibir información para el ejercicio pleno de la libertad de expresión, la difusión de valores como la identidad, la diversidad cultural y el apoyo a la educación; el derecho de todas las personas a fundar, instalar y operar cualquier clase de servicio de comunicación audiovisual; y tres modalidades de servicios de comunicación audiovisual: comerciales, públicos y comunitarios. Además, crea un fondo de promoción de la producción audiovisual, mecanismos para la programación de las producciones nacionales y culturales; y el Instituto Nacional de Derechos Humanos y Defensoría del Pueblo encargada de "defender y promover los derechos de las personas hacía y ante los servicios de comunicación audiovisual, en particular su derecho a difundir, buscar y recibir ideas e informaciones" (Artículo 85).

En la Ley No. 19.307 no se observa el uso de lenguaje inclusivo, salvo cuando se refieren a niños y niñas. Tampoco se define el concepto de "género". Aunque la Ley promueve en los medios masivos el respeto por los derechos humanos de las mujeres y el tratamiento de la violencia desde la perspectiva de género, no tiene mecanismos para la producción de contenidos con perspectiva de género. Por su parte, la ley sí contempla prohibiciones de varios contenidos discriminatorios entre ellos por razón de género e incluyen en la Comisión Honoraria Asesora de Servicios de Comunicación Audiovisual tres representantes de organizaciones no gubernamentales que, entre otras áreas, se dediquen a la defensa de los derechos de niños, niñas adolescentes, mujeres y eliminación de toda forma de discriminación. En cuanto a género, Ley $N^{\circ} 18.104$ de lgualdad de Derechos y Oportunidades entre hombres y mujeres (15.III.2007) no menciona artículos relacionados con la comunicación o medios de comunicación.

Finalmente, México en su Ley Federal de Telecomunicaciones y Radiodifusión menciona algunos aspectos relacionados a género. Principalmente desde la regulación de publicidad y de contenidos, pero se habla de discriminación en términos generales y no precisamente desde el género, solo en algunos casos como el artículo 226, en el cual se indica que se debe "Promover el derecho de las mujeres a una vida libre de violencia" (Cámara de Diputados, 2016). Ley General para la Igualdad entre Mujeres y Hombres de México, tal como lo indica su nombre, está muy enfocada a promover la igualdad entre géneros y no a uno en particular. La Ley sí presenta algunos aspectos relacionados con comunicación, como lo son el "Velar porque los medios de comunicación transmitan una imagen igualitaria plural y no estereotipada de mujeres y hombres en la sociedad, promuevan el conocimiento y la difusión del principio 
de igualdad entre mujeres y hombres y eviten la utilización sexista del lenguaje" (Artículo 42) y otros como la promoción de campañas de concientización.

\section{Las leyes del pasado}

La región centroamericana sigue siendo una de las más atrasadas en los debates sobre comunicación y sobre género, por separado y de manera transversal aún más. Es importante notar que las leyes marco de comunicación de Costa Rica y El Salvador (a pesar de que presentan algunas modificaciones recientes) siguen siendo leyes rezagadas, pues no presentan cambios grandes ni estructurales. Son legislaciones prácticamente pensadas desde lo regulatorio exclusivamente, y no desde el derecho a la comunicación.

Con respecto a la transversalización de género y comunicación, Costa Rica es, posiblemente, el país más rezagado de los nueve que aquí se analizan, ya que ni en la ley de radio ni en la de telecomunicaciones menciona nada sobre género. Asimismo, la Ley de Promoción de la Igualdad Social de la Mujer de Costa Rica tampoco cumple con la transversalización, debido a que no contiene nada referente a medios de comunicación. Como excepción, la Ley No. 5811, la cual tiene como fin regular la propaganda que utilice la imagen de la mujer, sí habla sobre comunicación, sin embargo, lo hace desde el conservadurismo, el pudor y la censura y no desde un análisis de perspectiva de género. Cabe destacar que esta es una ley fue articulada desde 1975 y cuenta con apenas 15 artículos.

Para el caso de El Salvador en su Ley General de Telecomunicaciones tampoco transversaliza la perspectiva de género, pues es un tema invisibilizado. Dicha perspectiva tampoco fue tomada en cuenta en el recién aprobado Proyecto de Reformas a la Ley General de Telecomunicaciones. Por tal razón, es claro que para el sector de la comunicación, en este país, la problematización de género no es un tema prioritario.

Sin embargo, en los artículos 15 y 34 de la Ley de Igualdad, Equidad y Erradicación de la Discriminación contra las Mujeres de El Salvador sí se alude a temáticas relacionadas con la comunicación. Tal es el caso de la "Erradicación del Sexismo en el Lenguaje Institucional y Social" y "La Igualdad en la Acción de los Medios de Comunicación y la Publicidad del Estado", la cual promueve una mayor participación de las mujeres en los medios de comunicación. Si bien esta legislación incluye dichos artículos, desde la perspectiva de la transversalización con derecho a la comunicación, sigue siendo una ley atrasada; no obstante, está más avanzada que la de Costa Rica.

Así, tanto Costa Rica como El Salvador posee una legislación en comunicación "del siglo pasado", por lo que la vinculación con género está muy poco presente. Vinculado con el marco legal en género, El Salvador tiene una ley que contiene varios elementos relacionados con comunicación, los cuales son bastante rescatables, contrario al caso costarricense donde sus dos leyes 
referentes a género están desactualizadas; incluso, la que, de forma específica, vincula género y medios de comunicación.

\section{Instrumentos internacionales para transversalizar el género en clave de comunicacón}

Respecto a los instrumentos internacionales que sirven como fuente de interpretación explícita de la legislación relacionada con radiodifusión sonora y televisión, el más importante y citado es la Declaración Universal de Derechos Humanos, la cual afirma, entre otras cuestiones, tanto la igualdad en dignidad y el derecho de todos los seres humanos, como la igualdad ante la ley y la protección contra diversas formas de discriminación.

Otros instrumentos internacionales mencionados son la Convención Interamericana sobre Derechos Humanos, la Convención Americana de Derechos Humanos, la Convención sobre los Derechos del Niño, el Pacto Internacional de Derechos Civiles y Políticos, Declaración Universal de Derechos Humanos, la Convención sobre la Protección y Promoción de la Diversidad de las Expresiones Culturales de la UNESCO y Unión Internacional de Telecomunicaciones. En el ámbito del género, se incluyen la Convención para la Eliminación de Todas las Formas de Discriminación contra la Mujer (CEDAW de 1979), la Declaración de Naciones Unidas sobre la Eliminación de la Violencia contra la Mujer (1993) y la Convención Interamericana para Prevenir, Sancionar y Erradicar la Violencia contra las Mujeres, conocida como Belém do Pará y aprobada por la Organización de Estados Americanos en 1994.

Al contar la frecuencia con que se citan convenciones, declaraciones y pactos, destaca que los instrumentos internacionales más mencionados hacen referencia a la eliminación de la discriminación y la violencia contra las mujeres, y los derechos de la niñez. Se citan la Convención Interamericana para Prevenir, Sancionar y Erradicar la Violencia contra las Mujeres, conocida como Belém do Pará y aprobada por la Organización de Estados Americanos en 1994, la Convención para la Eliminación de Todas las Formas de Discriminación contra la Mujer (CEDAW) de 1979; y la Convención sobre los Derechos del Niño de 1989. Entre 3 y 6 países de los 9 analizados hacen mención explícita a estos instrumentos internacionales (Castro-Camacho, Cubero-Hernández y Ochoa-Chaves, 2017).

La CEDAW'12 es el principal instrumento y el de más alto nivel en cuanto a la promoción de la igualdad y la prohibición de la discriminación en todos los Estados. Este se basa en tres principios centrales: el principio de igualdad sustantiva, el principio de no discriminación y el principio de obligación del Estado (Consejo Nacional para la Igualdad de Género, Ecuador, 2015, p. 43).

12 Cuando un Estado es parte de la CEDAW, voluntariamente acepta una gama de obligaciones legalmente vinculantes para eliminar todas las formas de discriminación contra las mujeres y garantizar la igualdad entre hombres y mujeres. 
En la Agenda Nacional de Igualdad de Género de Ecuador (Ecuador, 2015) al referirse a la CEDAW se indica que: "El principio de igualdad sustantiva promueve un modelo que comprende la igualdad de oportunidades, de acceso a las oportunidades y de resultados"; en el principio de la no discriminación se exige que "se reconozcan aquellos tipos de discriminación que no son obvios o directos" (p. 35), desde la perspectiva del derecho a la comunicación serían el reconocimiento de las violencias mediáticas y simbólicas.

Tabla 3: Instrumentos más citados en las leyes analizadas

Instrumento internacional

Convención sobre la Eliminación de todas formas de

Discriminación contra la Mujer, CEDAW (1979)

Convención Interamericana para Prevenir, Sancionar y Erradicar la Violencia contra las Mujeres, Belém do Pará (1994)

Convención sobre los Derechos del Niño (1989)

Declaración Universal de Derechos Humanos (1948)

Pacto Internacional de Derechos Civiles y Políticos (1966)

Convención Americana de Derechos Humanos (1969)
Países que lo mencionan

Argentina

Costa Rica

Ecuador

El Salvador

Paraguay

Venezuela

Argentina

Bolivia

Ecuador

Paraguay

Venezuela

Argentina

Ecuador

Paraguay

Ecuador

Paraguay

Uruguay

Ecuador

Paraguay

Uruguay

Argentina

Ecuador

Fuente: Castro-Camacho, Cubero-Hernández y Ochoa-Chaves, 2017. 


\section{Acciones afirmativas relacionadas con transversalización de género en clave de derecho a la comunicación}

El análisis de las acciones afirmativas para transversalizar el género en las políticas de comunicación se realizó a partir de seis diferentes focos: promoción de contenidos que prevengan la desigualdad de género, fondos para la producción y promoción de iniciativas, regulación de contenidos y publicidad, generación de institucionalidad, capacitaciones en comunicación y género a miembros del gobierno o los medios y, finalmente, la creación de una figura de defensoría de la audiencia.

\section{Promoción de contenidos que prevengan la desigualdad de género}

El promover contenidos que favorezcan la igualdad y ayuden a reconfigurar la forma como son tratadas las personas según su género, es el contenido que con mayor frecuencia está presente en las políticas públicas estudiadas. Las medidas varían dentro de cada país, pero siguen líneas similares. En Bolivia se encarga al Ministerio de Comunicación el diseño e implementación de una estrategia nacional de comunicación con campañas en medios masivos, con el fin de sensibilizar a la población sobre la violencia contra las mujeres, erradicar estereotipos patriarcales de subordinación y desvalorización de las mujeres. La legislación argentina establece que el Sistema Nacional de Medios está en la obligación de difundir entre la población mensajes y campañas permanentes de sensibilización y concientización sobre el derecho de las mujeres a vivir una vida libre de violencia. Paraguay sigue en la misma línea, al plantear campañas comunicativas de género, que difundan una imagen no discriminatoria y libre de estereotipos sexistas.

En Venezuela se establece concretamente un tiempo mínimo gratuito para la transmisión de mensajes en contra de la violencia basada en género y que promuevan la igualdad. Además, relacionado a lo institucional, se plantea la creación de programas de prevención y supervisión de la efectiva inclusión de contenido destinado a prevenir y eliminar la violencia contra las mujeres en las programaciones de los medios. Costa Rica, a pesar de que en sus leyes contempla el tema, lo hace desde un enfoque distinto. Los mensajes con perspectiva de género se encomiendan a la responsabilidad social empresaria y las campañas publicitarias para prevenir, más que al Estado. México, por su parte, incluye la perspectiva al plantear que los medios deben transmitir una imagen igualitaria, plural y no estereotipada de hombres y mujeres, no acciones concretas. 


\section{Fondos para la producción y promoción de iniciativas}

No existen fondos más allá de las campañas que financian los Estados, otras acciones no se mencionan en los documentos. El apoyo a iniciativas ciudadanas o de Organizaciones No Gubernamentales no se incluye y no hay ningún tipo de información sobre fondos para la producción de contenidos orientados en esta perspectiva.

\section{Regulación de contenidos y publicidad}

Todos los marcos legales de los países concuerdan al establecer una prohibición a la transmisión de mensajes que promuevan la discriminación religiosa, política, de género, raza, nacionalidad, orientación sexual, ideología, entre otros; pues están en contra de que se menoscabe la dignidad humana. Junto con la regulación de estos contenidos se da una muy importante, la de la publicidad que transmiten los medios. La Ley Orgánica de Telecomunicaciones de Ecuador (Cámara de Diputados, 2016) es ejemplo de ambas. Por un lado, luefo define contenido discriminatorio como "todo mensaje que se difunda por cualquier medio de comunicación social que connote distinción, exclusión o restricción" basada en los aspectos ya mencionados (Artículo 61). Por el otro, el artículo 94 establece que no se permitirá la publicidad que induzca a la violencia, la discriminación, el racismo, la toxicomanía, el sexismo y la intolerancia religiosa o política. Obliga a las agencias de publicidad a "abstenerse de incluir mensajes sexistas, discriminatorios, racistas o que violen los derechos fundamentales de las personas" (Artículo 53).

En este aspecto la perspectiva de las leyes en Costa Rica difiere conceptualmente: en lugar del género, se aborda desde la moral. La Ley No. 5.811 establece que "todo tipo de propaganda comercial que ofenda la dignidad, el pudor de la familia y en la que se utilice la imagen de la mujer impúdicamente, para promover las ventas, será controlada y regulada" (Asamblea Legislativa de la República de Costa Rica, 1975, Artículo 1).

\section{Generación de institucionalidad}

Ecuador es el único país que alude a la composición laboral de los medios de comunicación, no de instituciones o medios estatales, debe basarse en criterio de equidad y paridad entre hombres y mujeres. También menciona al Consejo de Regulación y Desarrollo de la Información y Comunicación (CORDICOM), que realiza estudios e investigaciones para determinar la presencia y el grado de discriminación en los medios, así como sensibilización acerca de las formas en que actúa la discriminación en la sociedad y acciones con medios para prevenir daño en los contenidos que tratan sobre grupos vulnerables. La ley uruguaya menciona que la Comisión Honoraria Asesora 
de Servicios de Comunicación Audiovisual, debe incluir 3 representantes de ONG cuya finalidad incluya la defensa de los derechos de niños, niñas adolescentes, mujeres y eliminación de toda forma de discriminación.

La institucionalidad en la legislación mexicana se orienta en la creación de mecanismos que permitan la denuncia y adopción de medidas concretas contra los medios que difundan mensajes sexistas o promuevan la imagen de la mujer como objeto sexual o cualquier clase de violencia de género. Asimismo en fortalecer métodos de promoción de la igualdad entre mujeres y hombres, mediante instancias administrativas a nivel estatal y del Distrito Federal.

\section{Capacitaciones en comunicación y género}

Las medidas para propiciar la capacitación del personal tanto de los medios de comunicación como de instituciones estatales se define únicamente y de manera explícita en Bolivia, Paraguay y Argentina. En este este último caso, recae en la Secretaría de Medios de Comunicación de la Nación.

\section{Figura de defensoría de la audiencia}

La creación de una figura de defensa de la audiencia se concreta en Ecuador y Argentina. En el primer caso se denomina Defensor de las audiencias y corresponde a una figura que los medios de alcance nacional tienen que incluir necesariamente. El objetivo es que genere interactividad con sus audiencias y lectores, y espacios para la publicación de errores y correcciones. En Argentina, por su parte, se designa como Defensoría del Público de Servicios de Comunicación Audiovisual. Su labor principal es "recibir y canalizar consultas, reclamos y denuncias del público de la radio y la televisión y demás servicios audiovisuales" (Artículo 19). Igualmente debe incluir a organizaciones públicas o privadas, centros de estudios e investigación u otras entidades, en un debate permanente sobre el desarrollo y funcionamiento de los medios de comunicación (Presidencia de la Nación, 2010, Artículo 19).

\section{Otros aspectos}

Es importante recalcar algunas acciones afirmativas que no entran en las categorías planteadas y que corresponden a iniciativas exclusivas de distintos países. En Venezuela, por ejemplo, la Ley Orgánica sobre el Derecho de las Mujeres a una Vida libre de Violencia (Asamblea Nacional de la República Bolivariana de Venezuela, 2007) sanciona a el o la profesional de la comunicación que en su trabajo "ofenda, injurie, denigre a una mujer por razones de género a través de un medio de comunicación" (Artículo 53). El o la responsable deberá indemnizar económicamente a la víctima y hacer públicas sus disculpas por el mismo medio utilizado para hacer la ofensa. 
Finalmente, la ley boliviana incluye dentro de las obligaciones de los medios, la incorporación y seguimiento de códigos de ética y otras medidas para la autorregulación, en cuanto a contenidos discriminatorios que afecten negativamente a las mujeres.

\section{Conclusiones: Lineamientos para la transversalización}

Respecto a la transversalización entre género y comunicación, la mayoría de las leyes estudiadas se quedan en la parte de regulación de la publicidad y promoción de contenidos no discriminatorios. Hace falta que la comunicación se vea más como una acción para el cambio social, lo que conlleva campañas masivas de comunicación y también comunitarias, asimismo, capacitación en herramientas de comunicación tanto para las personas que trabajan género como en formación de género para las personas que trabajan en comunicación y medios.

En este sentido, se puede avanzar en diversas acciones afirmativas que aborden tres ámbitos: La distribución del espectro radioeléctrico, el reconocimiento y protección de derechos humanos en los contenidos y el fortalecimiento de la producción nacional con perspectiva de género. Es necesario abrir el espectro a las mujeres y a poblaciones con identidades o expresiones de género diversas, no dominantes, facilitar la creación de medios comerciales y comunitarios por parte de colectivos de mujeres y organizaciones sociales con perspectiva de género.

Desde el reconocimiento y protección de derechos humanos en los contenidos, hay que ampliar la prohibición de contenidos discriminatorios no solo por sexo, sino también por identidad de género y orientación sexual. Además, es necesario trabajar por el reconocimiento y prohibición de contenidos que impliquen violencia simbólica y mediática en contra de las mujeres, por la creación de institucionalidad como las defensorías de la audiencia, para contar con instancias para demandar el respecto de los derechos humanos en el ámbito de los contenidos.

Desde la producción de contenidos, generar fondos de producción nacional para contenidos que prevengan la desigualdad de género y promuevan una perspectiva de equidad, producción nacional hecha por mujeres y para mujeres, por grupos sexualmente diversos y para su propia resignificación y orgullo, para explorar otras formas de contar y de narrar. Por último, es necesario hacer explícita la vinculación entre las leyes de equidad o igualdad de género, con las leyes de telecomunicaciones y de responsabilidad social de los medios de comunicación. 


\section{Referencias}

Abela, Jaime Andréu. (2013). Las técnicas de Análisis de Contenido: Una revisión actualizada. Recuperado de http://public.centrodeestudiosandaluces.es/pdfs/S200103.pdf

Andrade, Fernando. (2007). El Derecho a la Comunicación como eje articulador de la ética política en democracia. Punto Cero 12(14). Recuperado de http://www.scielo.org.bo/scielo.php?script=sci_arttext\&pid $=$ S1815-02762007000100006

Araya, Lisbeth, Avendaño, Adrián y Carazo, Eva. (2013). La comunicación como derecho: un acercamiento a la legislación costarricense en el contexto de otras legislaciones latinoamericanas. Anuario de Estudios Centroamericanos, 39, 343-371. Recuperado de https://revistas.ucr.ac.cr/ index.php/anuario/article/view/11810/11132

Cámara de Senadores. (2016). Proyecto de ley integral de violencia basada en género. Recuperado de https://parlamento.gub.uy/noticiasyeventos/ noticias/node/86302

Artículo 19. (2011). Venezuela: Ley de responsabilidad social en servicios de radio, televisión y medios electrónicos. Recuperado de https://goo.gl/Ag9UqB

Asamblea Legislativa de la República de Costa Rica. (1954). Ley de Radio. No. 1.758. Costa Rica: Tribunal Supremo de Elecciones Normativa. Recuperado de https://goo.gl/NKkNKv

Asamblea Legislativa de la República de Costa Rica. (1975). Ley No. 5.811. Regula Propaganda que Utilice la Imagen de la Mujer. Costa Rica. Recuperado de https://goo.gl/DWuAem

Asamblea Legislativa de la República de Costa Rica. (1990). Ley No. 7.142. Ley de Promoción de la Igualdad Social de la Mujer. Costa Rica. Recuperado de https://goo.gl/TGe8jS

Asamblea Legislativa de la República de Costa Rica. (2008). Ley General de Telecomunicaciones. Ley No. 8642. Costa Rica: Gaceta. Recuperado de https://goo.gl/wafM91

Asamblea legislativa de la República de El Salvador. (2011). Ley de Igualdad, Equidad y Erradicación de la Discriminación contra las mujeres. No. 645. El Salvador. Recuperado de https://goo.gl/iQAujD

Asamblea Legislativa de la República de El Salvador. (2016). Ley de Telecomunicaciones. El Salvador:

Diario Oficial. Recuperado de https://goo.gl/xwFP6t 
Asamblea Legislativa Plurinacional. (2011). Ley general de telecomunicaciones, tecnologías de información y comunicación. Bolivia. Recuperado de https://goo.gl/TWZq4s

Asamblea Legislativa Plurinacional. (2013). Ley No. 348. Ley integral para garantizar a las mujeres una vida libre de violencia. Bolivia: Gaceta oficial del Estado Plurinacional de Bolivia. Recuperado de https://goo.gl/dSZ8DP

Asamblea Nacional Constituyente. (2011). Ley orgánica de telecomunicaciones. Venezuela. Gaceta oficial de la República Bolivariana de Venezuela. Recuperado de https://goo.gl/C4bJA2

Asamblea Nacional de la República Bolivariana de Venezuela. (2007). Ley Orgánica sobre el derecho de las mujeres a una vida Libre de violencia. Venezuela: Gaceta oficial de la República Bolivariana de Venezuela. Recuperado de https://goo.gl/v6avZA

Asamblea Nacional de la República Bolivariana de Venezuela. (2011). Ley de Responsabilidad Social en Radio, Televisión y Medios Electrónicos. Venezuela: Gaceta oficial de la República Bolivariana de Venezuela. Recuperado de http://www.conatel.gob.ve/files/leyrs06022014.pdf

Asamblea Nacional República del Ecuador. (2008). Constitución de la República del Ecuador. Ecuador. Recuperado de https://goo.gl/axmmCx

Asamblea Nacional República del Ecuador. (2013). Ley orgánica de comunicación. Recuperado de https://goo.gl/GmAo3y

Cámara de Diputados. (2016). Ley Federal de Telecomunicaciones y Radiodifusión. Diario Oficial de la Federación. México. Recuperado de https://goo.gl/c2E12v

Cámara de Senadores. (18 de octubre de 2016). PROYECTO DE LEY INTEGRAL DE VIOLENCIA BASADA EN GÉNERO | Parlamento. Recuperado 16 de agosto de 2017, de https://goo.gl/t62Mmr

Carazo, Eva. Ochoa, Luisa. (2016). Costa Rica: La propuesta participativa de Ley de Radio y Televisión, retos y experiencias desde la ciudadanía. Sistematización REDMICA. Sin publicar

Castro-Camacho, M. A., Cubero-Hernández, E. y Ochoa-Chaves, L. (2017). Género, comunicación y políticas públicas: una mirada a la transversalización del género y derecho a la comunicación en América Latina. Presentado en IAMCR - Internacional Association for Media and Comunicacion Research, Cartagena. 
Chaher, Sandra. (2014). Políticas públicas de comunicación y género en América Latina: un camino por recorrer. Buenos Aires: Comunicación para la igualdad.

Chaher, Sandra. (2016). Políticas públicas de comunicación y género en América Latina: Entre andares y retrocesos. Buenos Aires: Comunicación para la igualdad. Recuperado de https://goo.gl/wodskW

Congreso Nacional del Ecuador. (1995). Ley contra la violencia a la mujer y a la familia. Ecuador. Recuperado de https://goo.gl/6JP3CA

Consejo Nacional de Igualdad de Género. (2015). Agenda Nacional de igualdad de género. Secretaría Nacional de Planificación y Desarrollo 20142017. Recuperado de https://goo.gl/MZzzVa

Constante, Soraya. (25 de junio 2015). Ecuador ha sancionado a casi 200 medios en dos años. Quito. Recuperado de https://goo.gl/H4bE25

Cubero, Esteban. (2016). Género, Comunicación y Política Pública. Revista Vacío. Recuperado de http://revistavacio.com/genero/

Diario de Cuba. (25 de noviembre de 2015). El gobierno de Correa ha sancionado a 198 medios de prensa en dos años. Recuperado de https://goo. $\mathrm{gl} / \mathrm{yfeUvq}$

Gómez Germano, Gustavo. (2014). La regulación de medios y la televisión digital en América Latina. Situación actual, tendencias y desafíos. Banco Mundial. Recuperado de https://goo.gl/KGJhNL

Gómez Germano, Gustavo. (30 de marzo de 2016). Los cambios por decreto a ley de medios en Argentina y su impacto en la diversidad y el pluralismo. Recuperado de https://goo.gl/Nv9HNu

Herrera, Leonel. (2013). Derecho a la comunicación y democratización de los medios. En I Congreso centroamericano de comunicación: desafíos de la comunicación en Centroamérica. Costa Rica, San José.

Infobase. (29 de octubre de 2013). Los polémicos proyectos de ley de medios en América Latina. Recuperado de https://goo.gl/kGGPNA

Milenio Digital. (2017). ¿Qué artículos de la Ley de Telecomunicaiones Impugna la Presidencia? Recuperado de https://goo.gl/TFM3fG

Naciones Unidas. (1995). Declaración y Plataforma de Acción de Beijing. Plataforma de Acción de Beijing. Recuperado de https://goo.gl/vvfyzW

Observacom [Observatorio Latinoamericano de Regulación, Medios y Convergencia]. (2016). Sobre el marco legal venezolano. Recuperado de https://goo.gl/46ih1Q 
Observacom. (9 de mayo de 2016). El Salvador aprueba reforma de Ley de Telecomunicaciones que reconoce a las radios comunitarias. Recuperado de https://goo.gl/HMvuws

Observacom. (19 de julio de 2016). Comité Derechos Humanos de ONU preocupado por la Ley de Comunicación de Ecuador. Recuperado de https://goo.gl/n4ni9h

Presidencia de la Nación. (2010). Ley 26.522 Servicios de Comunicación Audiovisual y reglamentación. Boletín Oficial de la República Argentina. Recuperado de https://goo.gl/7EB2cn

Red de Investigadoras por la Vida y la Libertad de las Mujeres. (2008). Lineamientos y Mecanismos para una legislación de medios de comunicación con perspectiva de género. Recuperado de http://132.247.1.49/ mujeres/menu_superior/Doc_basicos/5_biblioteca_virtual/7_violencia/27.pdf

Saffon, Maria Paula. (2007). El derecho a la comunicación: un derecho emergente. Recuperado a partir de https://goo.gl/hBrfpb

Secretaría de la Mujer de la Presidencia de la República \& Fondo de Población de las Naciones Unidas-UNFPA. (2008). III Plan Nacional de igualdad de oportunidades entre hombres y mujeres 2008-2017. Paraguay. Recuperado de https://goo.gl/aRn7Ud

Senado y Cámara de Diputados. (14 de abril de 2009). Ley No. 26.485 de protección integral para prevenir, sancionar y erradicar la violencia contra las mujeres en los ámbitos en que desarrollen sus relaciones interpersonales. Boletín Oficial (Separata). Recuperado de https://goo.gl/g15kzs

Senado y la Cámara de Representantes de la República Oriental del Uruguay. (2005). Ley 17.930. Ley del Instituto nacional de las mujeres. Uruguay. Recuperado de https://goo.gl/oFx8uV

Senado y la Cámara de Representantes de la República Oriental del Uruguay. (2007). Ley No 18.104 de Igualdad de derechos y oportunidades entre hombres y mujeres en la república. Uruguay. Recuperado de https://goo.gl/1JeB9Y

Senado y la Cámara de Representantes de la República Oriental del Uruguay. (2014). Ley No. 19.307. Servicios de comunicación audiovisual. Uruguay. Recuperado de https://goo.gl/ERhEXx

Senado y la Cámara de Representantes de la República Oriental del Uruguay. (2009). Ley 18.620. Ley de derecho a la identidad de género y al cambio de nombre y sexo en documentos indentificatorios. Recuperado de https://goo.gl/DDFuTa 
Soto, Michael. (1 de junio de 2017). Empresario de TV: "No falta ley para pasar a tecnología digital”. Crhoy.com. Periódico Digital. Costa Rica Noticias 24/7. Recuperado de https://goo.gl/vs6LkU

Soto, Michael M. (5 de julio de 2017). Diputados buscan evitar "monopolio" de canales de TV. CRHoy.com. Periódico Digital. Costa Rica Noticias 24/7. Recuperado de https://goo.gl/hHbpny

Última Hora. (2017). Ley de audiovisual busca dar impulso al sector en Paraguay. Recuperado de http://www.ultimahora.com/ley-audiovisualbusca-dar-impulso-al-sector-paraguay-n1101362.html

Universidad de Costa Rica. (25 de noviembre de 2016). ¿Qué es la Ley Participativa? Recuperado de http://leyderadioytele.ucr.ac.cr/

Vargas, Ester. (19 de mayo de 2016). El Salvador aprueba reforma Ley de Telecomunicaciones, entrevista a Leonel Herrera habla desde el Salvador. PROLEDI. San José, Costa Rica. Recuperado de https://goo.gl/iv1EVg

Vega, Aimée. (2009). El derecho de las mujeres a la comunicación: la transversalización de la legislación de medios con perspectiva de género. Recuperado de https://goo.gl/H3CP4k

Viggiano, Martín. (27 de junio de 2017). Gobierno aplica la ley de medios y multa a canales por las tandas. El Observador. Recuperado de https:// goo.gl/G3KQzq 